\title{
Paradoxical expression of cell cycle inhibitor p27 in endometrioid adenocarcinoma of the uterine corpus - correlation with proliferation and clinicopathological parameters
}

\author{
J Watanabe*,', H Sato ${ }^{2}$, T Kanai ${ }^{2}$, Y Kamata ${ }^{2}$, T Jobo ${ }^{3}$, H Hata ${ }^{3}$, T Fujisawa ${ }^{2}$, E Ohno ${ }^{4}$, T Kameya' and \\ H Kuramoto ${ }^{2,3,4}$
}

'Department of Pathology, Kitasato University School of Medicine, I-15-I. Kitasato, Sagamihara, Kanagawa, 228-8555, Japan; ${ }^{2}$ Department of Clinical Cytology, Kitasato University Graduate School of Medical Sciences, I-15-I, Kitasato, Sagamihara, Kanagawa, 228-8555, Japan; ${ }^{3}$ Department of Obstetrics and Gynecology, Kitasato University School of Medicine, I- I 5- I, Kitasato, Sagamihara, Kanagawa, 228-8555, Japan; ${ }^{4}$ Department of Clinical Cytology, Kitasato University School of Allied Health Sciences, I-1 5-I, Kitasato, Sagamihara, Kanagawa, 228-8555, Japan

p27 is regarded as a cyclin-dependent kinase inhibitor of the GI-to-S cell cycle progression by suppressing the kinase activity of cyclin/ cyclin-dependent kinase complex. This study aimed to investigate p27 expression in the normal endometrium and endometrioid adenocarcinoma of the uterine corpus and the correlation of its expression with cell proliferation and clinicopathological parameters. Tissue samples of 127 endometrioid adenocarcinomas and 15 normal endometria were used in the study. Immunohistochemical staining for detecting p27 and Ki-67 was performed by the labelled streptavidin-biotin method on formalin-fixed and paraffinembedded tissue samples. The expression was given as the labelling index, which indicates the percentage of positive nuclei. p27 staining was observed in the nuclei of the glandular cells in the functional layer of the secretory phase endometrium, whereas it was negative in those of the proliferative phase. In endometrioid adenocarcinomas, the labelling index of p27 expression paradoxically increased more significantly in the higher histological grades and was correlated with that of Ki-67. The high level of p27 expression was associated with clinicopathological parameters such as FIGO stage, lymph node metastasis, lymphovascular space involvement and myometrial invasion. High p27 expression was linked to higher grades of endometrioid adenocarcinoma, cell proliferation and some clinical prognostic factors. These results indicate that p27 might be an indicator of poor prognosis.

British Journal of Cancer (2002) 87, 81 -85. doi:I0.1038/sj.bjc.660434 www.bjcancer.com

(C) 2002 Cancer Research UK

Keywords: p27; endometrium; endometrioid adenocarcinoma; cell proliferation; clinicopathological parameter

Cyclin-dependent kinase inhibitor (CKI) inhibits the cell cycle progression by suppressing the kinase activity of a variety of cyclin/cyclin-dependent kinase (cdk) complexes (Sherr, 1996). Abnormal expression of CKI is thought to play an important role in tumorigenesis and the progress of tumours.

CKIs are classified into two major families; the Ink4 family and the Cip/Kip family. P27 belongs to the Cip/Kip family and binds preferentially to the cyclin $\mathrm{E} / \mathrm{cdk} 2$ and cyclin $\mathrm{D} / \mathrm{cdk} 4$ complexes, and inhibits the G1-to-S progression (Russo et al, 1996). p27 knock-out mice sustain a variety of abnormalities including increased body size, multiple organ hyperplasia, pituitary tumour, and sterility due to underdeveloped ovaries (Nakayama et al, 1996). Therefore, p27 is predicted to act as a tumour suppressor.

It has been generally accepted that decreased p 27 expression is related to poor prognosis in tumours of different histogenesis including lung (Kawana et al, 1998), oesophageal (Singh et al, 1998), colon (Loda et al, 1997), breast (Gillett et al, 1999), ovarian (Masciullo et al, 1999) and prostate cancers (Yanping et al, 1997).In contrast, it has also been reported that increased p27 expression is correlated with poor prognosis of the oesophagus (Anayama et al, 1998) and colon carcinoma (Cheng et al, 1999).

*Correspondence: J Watanabe; E-mail: watajun@med.kitasato-u.ac.jp Received 2 January 2002; revised 30 April 2002; accepted 8 May 2002
In fact, it is not clear whether p27 expression is correlated positively or inversely with prognosis.

In the endometrium, it was reported that p27 was expressed in the secretory phase, but less in the proliferative phase (Shiozawa et al, 1998; Bamberger et al, 1999). Its expression was also higher in endometrial hyperplasia than in the proliferative phase and was significantly increased when the former was treated with medroxyprogesterone acetate (Shiozawa et al, 1998). Two studies mentioned that p27 was strongly reduced in endometrial carcinoma (Ahn et al, 1998; Bamberger et al, 1999), whereas a recent study showed a trend of increased p27 protein staining with high grade endometrial carcinoma (Nycum et al, 2001). p27 expression in endometrial carcinoma still remains contradictory. This study aimed to investigate p27 expression by immunohistochemical staining and the correlation of its expression with histological grades, cell proliferation and clinicopathological parameters in endometrioid adenocarcinoma of the uterine corpus.

\section{MATERIALS AND METHODS}

\section{Materials}

Tissue samples of 127 cases of endometrioid adenocarcinomas consisting of 73 well-differentiated adenocarcinomas (G1), 26 moderately-differentiated ones (G2), 28 poorly-differentiated ones 
(G3)) and 15 cases of normal endometrium (five with proliferative phase, 10 with secretory phase) were surgically obtained at Kitasato University Hospital between 1986 and 2000. Informed consent was obtained from all of the patients. Pathological diagnosis was classified according to the FIGO classification (FIGO, 1989). The patients' ages ranged from 30 to 83 years with the median age of 56 years. No patients had received either adjuvant chemotherapy or radiotherapy before surgery.

\section{Immunohistochemistry}

Immunohistochemical staining for p27 and Ki-67 were performed with the labelled streptavidin-biotin method (DAKO, Kyoto, Japan). Tissue samples fixed in $10 \%$ formalin and embedded in paraffin were sectioned to $3 \mu \mathrm{m}$ and deparaffinized in xylene. Endogenous peroxidase activity was blocked by 3\% hydrogen peroxide for $30 \mathrm{~min}$. Then, antigen retrieval was performed by autoclave at $121^{\circ} \mathrm{C}$ for $15 \mathrm{~min}$ in $0.1 \mathrm{mM}$ citrate buffer $(\mathrm{pH} \mathrm{6.0)}$. After being incubated with $10 \%$ normal swine serum for $30 \mathrm{~min}$, mouse monoclonal anti-human p27 antibody (clone 1B4, 1:200, Novocastra, Newcastle, UK) and rabbit polyclonal anti-human Ki-67 antibody (1:50 DAKO, Kyoto, Japan) were applied to the slides overnight at $4^{\circ} \mathrm{C}$, respectively. As negative controls, normal mouse or rabbit serum at the same dilution was used. Diaminobenzidine reaction was done for visualisation of the signal and Mayer's haematoxylin was used for counterstaining.
The percentage of positive nuclear staining of p27 was evaluated by counting at least 1200 cells in high power fields independently by two observers and expressed as the labelling index (LI). They were blinded as to the pathological parameters. Interobserver variation was addressed by averaging the individual values. Its variation usually did not differ by more than $10 \%$.

\section{Measurement of oestrogen receptor (ER) and progesterone receptor $(\mathbf{P R})$}

Oestrogen receptor (ER) and progesterone receptor (PR) in tumour tissue freshly obtained at surgery were measured using the radioreceptor assay system of Kitasato Biochemical Laboratory (Kanagawa, Japan). ER and PR were defined as positive when gross bound count/non-specific bound count $>2, \mathrm{Kd}<1 \mathrm{nM}^{-1}$ and (straight line recurrence coefficient) $>0.9$.

\section{Statistical analysis of immunostaining}

Statistical analysis of the correlation between LI of p27 and Ki-67 in the same patient was conducted by the Spearmann rank correlation test. The Mann-Whitney $U$-test was used to examine the correlation between LI of p27 and clinicopathological parameters. $P$-values less than 0.05 were considered significant.
A

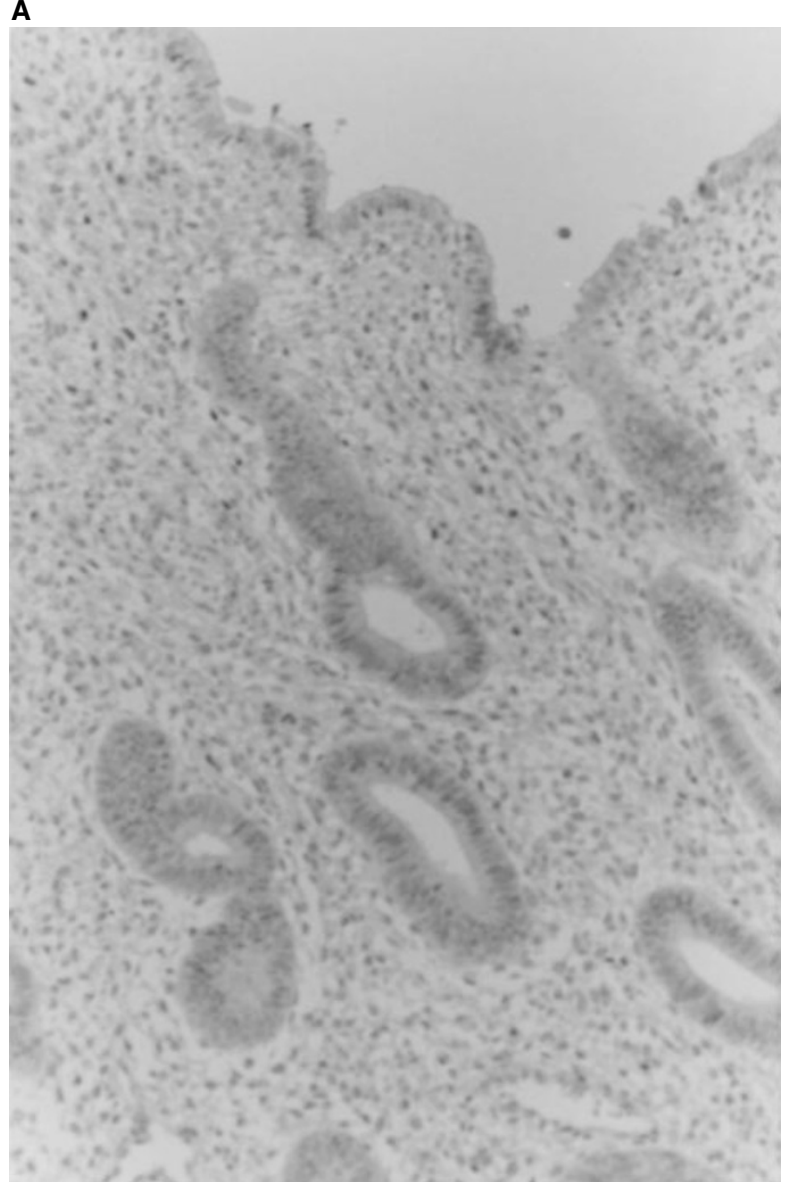

B

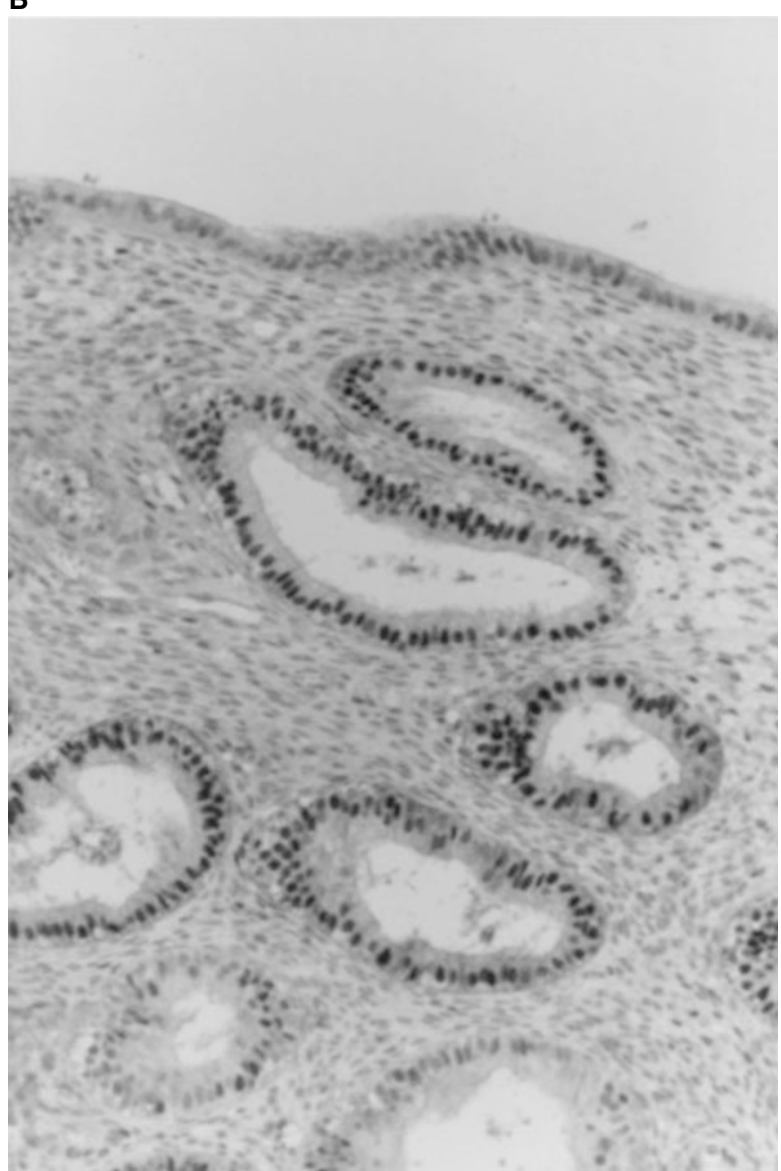

Figure I Immunohistochemical staining of p27 in normal endometrium. In the proliferative phase, the nuclei of the glandular cells in the functional layer are negative for p27 (A). In the secretory phase, the nuclei of the superficial lining cells and the glandular cells in the functional layer show positive for p27 (B). (Original magnification, $\times 200)$. 


\section{RESULTS}

\section{p27 expression in normal endometria}

In the proliferative phase, the glandular cells in the functional layer were negligible for p27 (Figure 1A). In the secretory phase, the nuclei of the superficial lining cells and the glandular cells of the functional layer were positive for p27 (Figure 1B).

\section{p27 expression in endometrioid adenocarcinomas}

p27 staining was positive in the nuclei of endometrioid adenocarcinomas and the positive rate of all cases was 97.6\% (124 out of 127 cases). The LIs of p27 expression in G1, G2 and G3 of endometrioid adenocarcinomas were $55.1 \pm 25.0,64.4 \pm 15.1$ and $75.0 \pm 10.7 \%$, respectively. The LIs increased significantly in the higher histological grades (Table 1); Figure 2A,B).

Although weak in comparison with the nuclei, p27 staining in the cytoplasm was also observed in $67.1 \%$ of G1 cases (49 out of 73 cases), $61.5 \%$ of G2 (16 out of 26 cases) and $25.0 \%$ of G3 (seven out of 28 cases), respectively.

\section{The correlation of p27 expression with Ki-67 expression}

Positive staining of KI-67 was observed in the nuclei of endometrioid adenocarcinomas of the uterine corpus. LI of p27 expression was significantly correlated with that of Ki-67 $(\mathrm{Rs}=0.226, P=0.017$ ) (Figure 3).

Table I Correlation between p27 expression and clinicopathological parameters in endometrial adenocarcinoma of the uterine corpus

\begin{tabular}{|c|c|c|c|}
\hline $\begin{array}{l}\text { Clinicopathological } \\
\text { parameters }\end{array}$ & $\begin{array}{l}\text { No. of } \\
\text { cases }\end{array}$ & $\begin{array}{l}\text { p27 LI (\%) } \\
\text { Mean } \pm \text { SD }\end{array}$ & P-value \\
\hline \multicolumn{4}{|l|}{ Histological grade } \\
\hline Gl & 73 & $\left.55.1 \pm 25.0\}^{\text {a) }}\right)^{\text {c) }}$ & a) $P=0.04$ * \\
\hline G2 & 26 & $64.4 \pm 15.1\}$ & b) $P=0.03 *$ \\
\hline G3 & 28 & $75.0 \pm(0.7\}^{b)}$ & c) $P=0.00 I^{*}$ \\
\hline \multicolumn{4}{|l|}{ Stage } \\
\hline FIGO I & 85 & $60.7 \pm 21.8$ & d) $P=0.03^{*}$ \\
\hline FIGO ॥ & 12 & $57.9 \pm 24.1$ & e) $P=0.48 *$ \\
\hline FIGO III & 27 & $61.1 \pm 19.8 r^{f)}$ & f) $P=0.03^{*}$ \\
\hline FIGO IV & 3 & $77.4 \pm 4.9\}$ & \\
\hline \multicolumn{4}{|l|}{ Lymph node metastasis } \\
\hline negative & 102 & $57.7 \pm 22.8$ & \\
\hline positive & 13 & $75.8 \pm 13.2$ & $P<\left.0.00\right|^{*}$ \\
\hline \multicolumn{4}{|l|}{ LVSI } \\
\hline negative & 87 & $56.6 \pm 23.2$ & \\
\hline positive & 30 & $72.2 \pm 13.3$ & $P<0.00 \mid *$ \\
\hline \multicolumn{4}{|l|}{ Myometrial invasion } \\
\hline subserosal & 112 & $60.2 \pm 22.0$ & \\
\hline serosal & 6 & $71.9 \pm 8.7$ & $P=0.042 *$ \\
\hline \multicolumn{4}{|l|}{ Group } \\
\hline I & 56 & $61.4 \pm 19.7$ & \\
\hline 2 & 52 & $60.4 \pm 21.7$ & N.S. \\
\hline 3 & 16 & $57.8 \pm 27.9$ & \\
\hline \multicolumn{4}{|l|}{ ER } \\
\hline positive & 56 & $61.1 \pm 23.0$ & \\
\hline negative & 44 & $65.3 \pm 17.9$ & N.S. \\
\hline \multicolumn{4}{|l|}{ PR } \\
\hline positive & 50 & $63.2 \pm 21.2$ & \\
\hline negative & 49 & $63.1 \pm 18.8$ & N.S. \\
\hline \multicolumn{4}{|l|}{ Menopause } \\
\hline Pre & 39 & $61.5+24.6$ & \\
\hline Post & 88 & $60.7 \pm 20.1$ & N.S. \\
\hline
\end{tabular}

*P<0.05: significant. N.S.: not significant. KI: labelling index. LVSI: lymphovascular space involvement. Group I: coexisting with endometrial hyperplasia. Group 2: coexisting with normal endometrium. Group 3: entirely replaced by carcinoma. MannWhitney U-test.

\section{A}

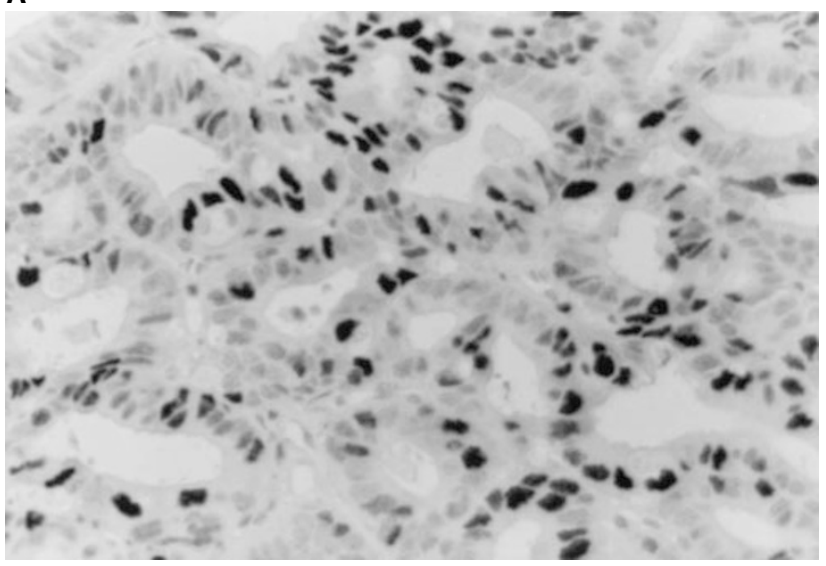

B

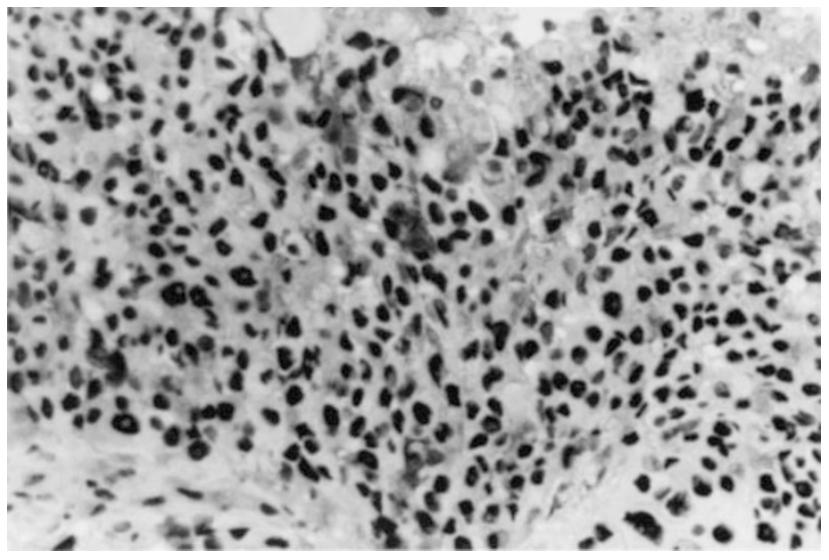

Figure 2 Immunohistochemical staining of p27 in endometrioid adenocarcinoma. The nuclei of GI (A) and G3 (B) of endometrioid adenocarcinoma show positive for p27. (Original magnification, $\times 400$ ).

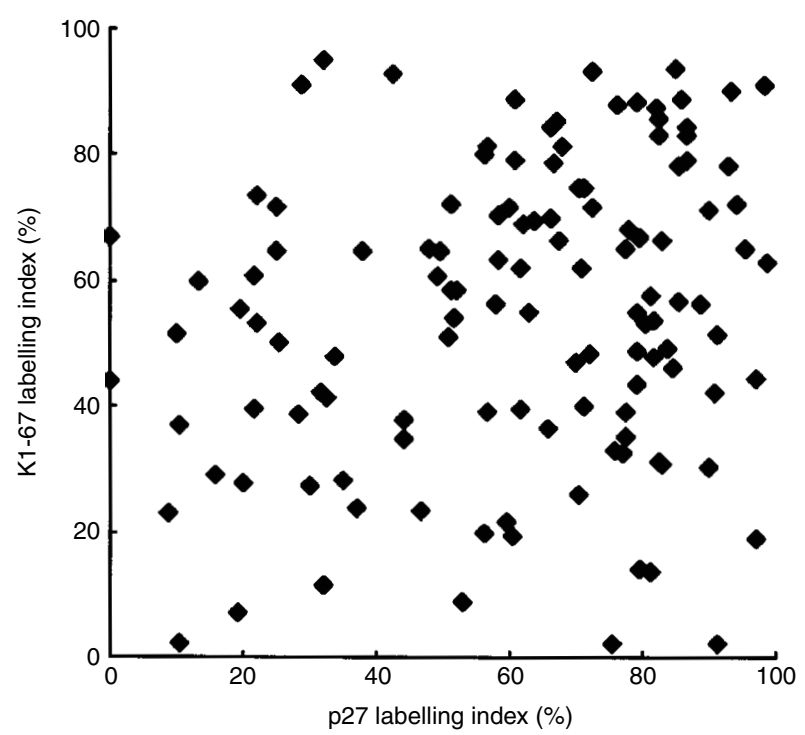

Figure 3 Correlation of p27 expression with Ki-67. LI of p27 was significantly correlated with that of Ki-67 in endometrioid adenocarcinoma of the uterine corpus. 
The correlation between p27 expression and clinicopathological parameters

The high level of p27 expression was significantly correlated with the clinicopathological parameters such as FIGO stage I vs IV $(P=0.03)$, II vs IV $(P=0.048)$, and III vs IV $(P=0.03)$, lymph node metastasis $(P<0.0001)$, lymphovascular space involvement (LVSI) $(P<0.0001)$ and myometrial invasion $(P=0.042)$. In contrast, it was not correlated with Group (Group 1: coexisting with endometrial hyperplasia, Group 2: coexisting with normal endometrium, Group 3: entirely replaced by carcinoma) (Ohkawara et al, 2000), ER and PR, and menopause (Table 1).

\section{DISCUSSION}

Our study showed that p27 staining was observed in the nuclei of the glandular cells in the secretory phase but negligible in the proliferative phase of normal endometrium. This result is the same as in previous reports (Shiozawa et al, 1998; Bamberger et al, 1999). Shiozawa et al (1998) suggested that a markedly increased p27 expression induced by progesterone in the secretory phase might develop cell growth arrest by inhibiting the cyclin E/cdk2 complex and it was a result of a persistent accumulation of p27 due to a prolonged half-life by progesterone-mediated impaired proteolytic activity.

Surprisingly, p27 expression in endometrioid adenocarcinoma of the uterine corpus increased significantly in the higher histological grades in our study. Two reports on endometrial adenocarcinoma demonstrated that decreased p27 expression was correlated with higher histological grade (Ahn et al, 1998; Bamberger et al, 1999). Recently, however, a trend associated with increased p27 staining with advanced grades of endometrial carcinoma was reported (Nycum et al, 2001). Our study showed that p27 expression was correlated with that of $\mathrm{Ki}-67$ as a proliferative marker. Similar results of a positive correlation between p27 expression and Ki-67 expression were reported in the colon (Cheng et al, 1999) and lung (Shoji et al, 1999). In some highly proliferative human breast cancer cells (Fredersdorf et al, 1997) and Burkitt's lymphoma cells (Barnouin et al, 1999), a high level p27 expression was seen. These results indicate that p27 expressed in carcinoma may not arrest the cell cycle progression.

A possible mechanism of p27 expression abnormality could be considered as follows: (1) its functional abnormality may be due to gene mutation. But no detectable cancer-specific mutations were found in a total of 147 human tumours (Ponce-Castaneda et al, 1995). Although polymorphism as a nucleotide substitution of guanine for thymine ( $\mathrm{GTC} \rightarrow \mathrm{GGC}$ ) at codon 109 was found in endometrial, uterine cervical and ovarian cancers, this polymorphism is also detected in normal cells (Kawamata et al, 1995). Deletions of the p27 gene have only been detected in B-immunoblastic non-Hodgkin's lymphomas and adult T-cell leukaemias/ lymphomas (Morosetti et al, 1995); (2) There may be a quantitative or structural abnormality of the cyclin E/cdk2 complex. There are two possibilities. One is an excessive amount of the complex beyond the inhibitory action of p27. The other is that p27 may act controversially as an assembly factor to stabilise the complex (Shoji et al, 1999); (3) Consumption of p27 may be trapped by other factors such as cyclin D1 and D3, which suppressed the formation of the complex (Fredersdorf et al, 1997; Tomoda et al, 1999); (4) p27 degradation by the ubiquitin-proteasome pathway in which skp2 is implicated (Carrano et al, 1999) may be disordered. Clarification of the precise mechanism of these possibilities, however, is left for a future study. Moreover, p27 may be overexpressed by a homeostatic feedback mechanism in overexpressed cases of p27, since high levels of cyclin E and cdk2 expressions are observed in these cases (Kawana et al, 1998; Cheng et al, 1999).

p27 expression in the cytoplasm has been reported in oesophageal (Gillett et al, 1999), colon (Fredersdorf et al, 1997) and ovarian carcinomas (Masciullo et al, 1999). Our analysis showed that p27 expression in the cytoplasm of endometrioid adenocarcinoma was reduced in the higher grade. With regard to this mechanism, it is suggested that unstable p27 is translocated from the nucleus to the cytoplasm by binding Jabl as the transreporter (Tomoda et al, 1999). Furthermore, a recent study shows that staining in the cytoplasm rather than in the nuclei is correlated with a recurrence and decreased survival (Singh et al, 1998). p27, which is localized in the cytoplasm, may not play a significant role in the prognosis of endometrial carcinoma, since p27 expression in endometrioid adenocarcinoma was predominant in the nuclei.

Our study showed that p27 expression in endometrioid adenocarcinomas was associated with prognostic factors, such as FIGO stage, lymph node metastasis, LVSI and myometrial invasion. There are variable views on the correlation between p27 expression and clinicopathological factors in various tumours. For example, low p27 expression was associated with prognostic factors in oesophageal (Singh et al, 1998) and ovarian carcinomas (Masciullo et al, 1999). It was also reportedly correlated with poor prognosis in colon (Loda et al, 1997) and breast carcinomas (Gillett et al, 1999) by univariate or multivariate analysis. In contrast, increased p27 expression was associated with poor prognosis in oesophageal (Anayama et al, 1998) and colon cancers (Fredersdorf et al, 1997). The majority of reports suggest that either high or low p27 expression is an independent prognostic factor. In endometrial carcinoma, it was reported that p27 expression was not associated with prognostic factors (Ahn et al, 1998; Bamberger et al, 1999; Nycum et al, 2001), whereas in our study the high expression was correlated with prognostic factors, since p27 protein expression increased in high grade and was associated with cell proliferation in our study.

p27 expression in endometrioid adenocarcinomas was not associated with hormone-related clinicopathological situations such as menopause, Group (Group 1: coexisting with endometrial hyperplasia, Group 2: coexisting with normal endometrium, Group 3: entirely replaced by carcinoma) (Ohkawara et al, 2000), and expression of ER or PR, although it was reportedly mediated by a progesterone-related hormonal environment in normal endometrium (Shiozawa et al, 1998). A recent study showed that antiestrogen-induced p21 and p27 via ER blocked entry of G1 phase cells into the $S$ phase by inhibiting cyclin D1 expression and cdk2 kinase activity in breast cancer cell lines (Watts et al, 1995). The relation between p27 expression and hormonal regulation in normal and neoplastic endometrial cells is left for further investigation.

In endometrioid adenocarcinoma of the uterine corpus, high p27 expression was linked to higher grade and Ki-67 expression, and may be paradoxical in the physiological action of p27. p27 expression was also correlated with clinical prognostic factors such as FIGO stage, lymph node metastasis, LVSI and myometrial invasion. Therefore, p27 expression might be an indicator of poor prognosis. We need more time to elucidate the relation between our results and our patients' actual prognosis.

\section{ACKNOWLEDGEMENTS}

This work was supported by grants-in - aid for the Project Research of Graduate School of Medical Sciences, Kitasato University and for Scientific Research from the Ministry of Education, Sciences and Culture (Grants 12670176 and 12671627), Japan. 


\section{REFERENCES}

Ahn HJ, Kwon WK, Choi Yja, Cho NH (1998) Expression of cyclin E and cyclin dependent kinase inhibitor, $\mathrm{p} 27^{\mathrm{KIP}}$ in uterine endometrial carcinoma relationship with p53 status. Int J Surg Pathol 6: 205-212

Anayama T, Furihata M, Ishikawa T, Ohtsuki Y, Ogoshi S (1998) Positive correlation between $\mathrm{p} 27^{\mathrm{KIP} 1}$ expression and progression of human esophageal squamous cell carcinoma. Int J Cancer 79: 439-443

Bamberger AM, Riethdorf L, Milde-Langosch K, Bamberger CM, Thuneke I, Erdmann I, Schulte HM, Loning T (1999) Strongly reduced expression of the cell cycle inhibitor p27 in endometrial neoplasia. Virchows Arch 434: $423-428$

Barnouin K, Fredersdorf S, Eddaoudi A, Mittnacht S, Pan LX, Du MQ, Lu X (1999) Antiproliferative function of $\mathrm{p} 27^{\mathrm{Kip} 1}$ is frequently inhibited in highly malignant Burkitt's lymphoma cells. Oncogene 18: 6388-6397

Carrano AC, Bytan E, Hershko A, Pagano M (1999) Skp2 is required for ubiquitin-mediated degradation of the Cdk inhibitor p27. Nat Cell Biol 1: $193-197$

Cheng JD, Werness BA, Babb JS, Meropol NJ (1999) Paradoxical correlations of cyclin-dependent kinase inhibitors p21waf1/cip1 and p2 $7^{\text {kip1 }}$ in metastatic colorectal carcinoma. Clin Cancer Res 5: 1057-1062

FIGO (1989) FIGO news. Int J Gynecol Obstet 28: 189-193

Fredersdorf S, Burns J, Milne AM, Packham G, Fallis L, Gillett CE, Royds JA, Peston D, Hall PA, Hanby AM, Barnes DM, Shousha S, O'Hare MJ, Lu X (1997) High level expression of $\mathrm{p} 27^{\mathrm{Kip} 1}$ and cyclin D1 in some human breast cancer cells: Inverse correlation between the expression of p27 $7^{\text {Kip } 1}$ and degree of malignancy in human breast and colorectal cancers. Proc Natl Acad Sci USA 94: 6380-6385

Gillett CE, Smith P, Peters G, Lu X, Barnes DM (1999) Cyclin-dependent kinase inhibitor $\mathrm{P} 27^{\mathrm{Kip} 1}$ expression and interaction with other cell cyclin-associated proteins in mammary carcinoma. J Pathol 187: 200-206

Kawamata N, Morosetti R, Miller CW, Park D, Spirin KS, Nakamaki T, Takeuchi S, Hatta Y, Simpson J, Wilcyznski S (1995) Molecular analysis of the cyclin-dependent kinase inhibitor P27/Kip1 in human malignancies. Cancer Res 55: 2266-2269

Kawana H, Tamaru J, Tanaka T, Hirai A, Saito Y, Kitagawa M, Mikata A, Harigaya K, Kuriyama T (1998) Role of p $27^{\text {Kip1 }}$ and cyclin-dependent kinase 2 in the proliferation of non-small cell lung cancer. Am J Pathol 153: $505-513$

Loda M, Cukor B, Tam SW, Lavin P, Fiorentino M, Draetta GF, Jessup JM, Pagano M (1997) Increased proteasome-dependent degradation of the cyclin-dependent kinase inhibitor p27 in aggressive colorectal carcinomas. Nature Med 3: $231-234$

Masciullo V, Sgambato A, Pacilio C, Pucci B, Ferrandina G, Palazzo J, Carbone A, Cittadini A, Mancuso S, Scambia G, Giordano A (1999) Frequent loss of expression of the cyclin-dependent kinase inhibitor p27 in epithelial ovarian cancer. Cancer Res 59: 3790-3794
Morosetti R, Kawamata N, Gombart AF, Miller CW, Hatta Y, Hirama T, Said JW, Tomonaga M, Koeffler HP (1995) Alterations of the p27Kip1 gene in non-Hodgkin's lymphomas and adult T-cell leukemia/lymphoma. Blood 86: $1924-1930$

Nakayama K, Ishida N, Shirane M, Inomata A, Inoue T, Shishido N, Horii I, Loh DY, Nakayama K (1996) Mice lacking p2 $7^{\text {Kip } 1}$ display increased body size, multiple organ hyperplasia, retinal dysplasia, and pituitary tumors. Cell 85: 707-720

Nycum LR, Smith LM, Farley JH, Kost ER, Method MW, Birrer MJ (2001) The role of p27 in endometrial carcinoma. Gynecol Oncol 81: 242-246

Ohkawara S, Jobo T, Sato R, Kuramoto H (2000) Comparison of endometrial carcinoma coexisting with and without endometrial hyperplasia. Eur J Gynaecol Oncol 21: 573-577

Ponce-Castaneda MV, Lee MH, Latres E, Polyak K, Lacombe L, Montgomery K, Mathew S, Krauter K, Sheinfeld J, Massague J (1995) p2 ${ }^{\text {Kip1 }}$ : Chromosomal mapping to 12 p12-12p13.1 and absence of mutation in human tumors. Cancer Res, 55: $1211-1214$

Russo AA, Jeffery PD, Patten AK, Massague J, Pavletich NP (1996) Crystal structures of the p27 $7^{\text {kip } 1}$ cyclin-dependent kinase inhibitor bound to the cyclinA-cdk2 complex. Nature 382: 325-331

Sherr CJ (1996) Cancer cell cycles. Science 274: $1672-1677$

Shiozawa T, Nikaido T, Nakayama K, Lu X, Fujii S (1998) Involvement of cyclin-dependent kinase inhibitor $\mathrm{p} 27^{\mathrm{kip} 1}$ in growth inhibition of endometrium in the secretory phase and of hyperplastic endometrium treated with progesterone. Mol Hum Reprod 9: 899-905

Shoji M, Dobashi Y, Morinaga S, Jiang S, Kameya T (1999) Tumor extension and cell proliferation in adenocarcinoma of the lung. Am J Pathol 154: 909-918

Singh SP, Lipman J, Goldman H, Ellis Jr FH, Aizenman L, Cangi MG, Signoretti S, Chiaur DS, Pagano M, Loda M (1998) Loss or altered subcelluar localization of p27 in Barrett's associated adenocarcinoma. Cancer Res 58: $1730-1735$

Tomoda K, Kubota Y, Kato J (1999) Degradation of the cyclin-dependent kinase inhibitor P27 $7^{\text {Kip } 1}$ is instigated by Jab1. Nature 398: $160-163$

Watts CKW, Brady A, Sarcevic B, deFazio A, Musgrov EA, Sutherland RL (1995) Antiestorogen inhibition of cell cycle progression in breast cancer cells is associated with inhibition of cyclin-dependent kinase activity and decreased retinoblastoma protein phosphorylation. Mol Endocrinol 9: $1804-1813$

Yanping G, Geoffrey NS, Andrew B, Natasha K (1997) Loss of the cyclindependent kinase inhibitor P27 ${ }^{\mathrm{Kip} 1}$ protein in human prostate cancer correlates with tumor grade. Clin Cancer Res 3: 2269-2274 